\title{
Effect of meloxicam and its combination with levofloxacin, pazufloxacin, and enrofloxacin on the plasma antioxidative activity and the body weight of rabbits
}

\author{
Adil Mehraj Khan and Satyavan Rampal \\ Department of Pharmacology and Toxicology, \\ College of Veterinary Sciences, Guru Angad Dev Veterinary and Animal Sciences (GADVASU), Ludihana, Punjab, India \\ Corresponding author: Adil Mehraj Khan, email: adi.adilmehraj@gmail.com
}

Received: 25-09-2013, Revised: 12-10-2014, Accepted: 14-10-2013, Published online: 01-12-2013

doi: 10.14202/vetworld.2013.950-954 How to cite this article: Khan AM and Rampal S (2013) Effect of meloxicam and its combination with levofloxacin, pazufloxacin, and enrofloxacin on the plasma antioxidative activity and the body weight of rabbits, Veterinary World 6(12): 950-954.

\begin{abstract}
Aim: Evaluation of meloxicam, levofloxacin, pazufloxacin, and enrofloxacin for their effect on the plasma antioxidative activity (AOA) and the body weight in rabbits.

Materials and Methods: Thirty two male Soviet Chinchilla rabbits were divided to eight groups of four rabbits each. Group A, serving as control, was administered $5 \%$ dextrose. Group B, C, E and G were gavaged meloxicam, levofloxacin, pazufloxacin and enrofloxacin, respectively, in 5\% dextrose. Levofloxacin and pazufloxacin were administered at the dose rate of $10 \mathrm{mg} / \mathrm{kg}$ body weight b.i.d $12 \mathrm{~h}$, whereas the meloxicam and enrofloxacin were administered at $0.2 \mathrm{mg} / \mathrm{kg}$ body weight o.i.d and $20 \mathrm{mg} / \mathrm{kg}$ body weight, respectively. Groups D, F and H were co-gavaged meloxicam with levofloxacin, pazufloxacin, and enrofloxacin, respectively, at the above dose rates. All these drugs were administered for 21 consecutive days. The plasma AOA and body weight was determined on $0,7,14$, and 21 day of treatment.
\end{abstract}

Results: The plasma AOA of meloxicam treated group was significantly lower than the control from $7^{\text {th }}$ day of treatment. On the $14^{\text {th }}$ day of treatment, the levofloxacin treated group had values significantly higher than the enrofloxacin-meloxicam cotreated group. Except for the levofloxacin treated group, a significant decrease in the antioxidative activity was observed in all treatment groups when compared to the control group on $21^{\text {st }}$ day of treatment. The body weight of all groups differed nonsignificantly throughout the study period.

Conclusion: The results from this study indicate that although these drugs have no effect on the body weight, a decrease in the plasma AOA is observed, especially when the duration of treatment is increased.

Key words: enrofloxacin, levofloxacin, meloxicam, pazufloxacin, plasma antioxidant activity

\section{I ntroduction}

Non-steroidal anti-inflammatory drugs (NSAIDs) are widely used drugs in both veterinary and human medicine for various inflammatory conditions of infectious or non-infectious origin [1]. NSAIDs act by inhibiting the pro-prostaglandin enzymes, cyclooxygenase-2 (COX-2), and cyclooxygenase-1(COX-1). The COX-2 inhibition is considered to mediate the therapeutic actions of NSAIDs, while the COX-1 inhibition usually results in unwanted side-effects, particularly in the gastrointestinal tract [1]. Meloxicam is a NSAID that has an apparently greater selectivity towards inhibition of inducible COX-2 isoform, than the constitutive isoform COX-1 [1].

Fluoroquinolones (FQs) are the quinolones with fluorine atom attached to the central ring system, typically at the C-6 position or C-7 position. These are bactericidal drugs that inhibit the bacterial enzymes DNA gyrase and topoisomerase IV and possess a broad spectrum of anti-bacterial activity against a range of bacteria, including the ones resistant to other anti-

Copyright: The authors. This article is an open access article licensed under the terms of the Creative Commons Attribution License (http://creativecommons.org/licenses/by/2.0) which permits unrestricted use, distribution and reproduction in any medium, provided the work is properly cited. microbial drugs [2]. Despite the basic similarity in the core structure of these molecules, their physiochemical properties, pharmacokinetic characteristics, and antimicrobial activities vary markedly across compounds [3]. Levofloxacin, the active L-isomer of the racemate ofloxacin, has nearly $100 \%$ oral bioavailability and is thus preferred over FQs that have broad spectrum of activities, but limited oral bioavailability [4]. It is used alone or in combination with other antibacterial drugs to treat certain bacterial infections, including pneumonia, urinary tract infections, and abdominal infections. Pazufloxacin, a fused tricyclic quinolone, has a 1 -aminocyclopropyl substituent at $\mathrm{C}-10$ position, a unique feature of the molecule contributing the potent broad spectrum activity to this drug [5]. It may be used as the drug of choice in community acquired infections, acute exacerbation of chronic bronchitis and postabdominal infection sepsis [6]. Enrofloxacin, a 6fluoro-7-piperazinyl-4-quinolone approved for veterinary use, has been evaluated as a method to eliminate Salmonella infections in cattle and poultry and manage several bacterial diseases in lagomorphs, from Pasteurella multocida to Mycoplasma spp. [7]. Oral dosing with enrofloxacin does not appear to develop antibiotic dysbiosis, which is common with 
penicillins and cephalosporins [7].

Although fluoroquinolones (FQs) are relatively safer drugs, certain adverse effects such as gastrointestinal discomfort, hepatotoxic reactions, central nervous system effects, juvenile joint toxicity, phototoxic and retinopathic effects, although rare, have been reported in association with their use [8]. In 2004, the FDA requested new warning labels to be added to all of the FQs, about irreversible peripheral neuropathy, rhabdomyolysis, tendon damage, pseudomembranous colitis, heart problems (prolonged QT Interval/Torsades de pointes), Stevens - Johnson syndrome, as well as concurrent usage of NSAIDs contributing to the severity of these reactions [9]. Some of the side effects of FQs, like phototoxicity [10] and cartilage defects [11] have been incriminated to the production of reactive oxygen species (ROS) [12]. Although, NSAIDs including meloxicam improve oxidative imbalance $[1,13,14]$, alteration of antioxidant levels has been reported with several NSAIDs [15] with studies demonstrating oxidative stress as the mechanism of their toxicity [16, 17]. An imbalance between the pro-oxidant and antioxidant moieties represents oxidative imbalance/ stress. Complete antioxidant profile of body fluids cannot be fully reflected by any single component of antioxidant complex, due to interactions that occur in vivo among different antioxidant components [18]. Total antioxi-dative activity (AOA) considers the cumulative effect of all antioxidants present in body fluids [19]. It could be used to assess the real change in antioxidant status in patients with severe infection and can thus make the treatment effective [20]. Complicated infections require weeks of antibiotic therapy and protracted course of NSAIDs to manage various associated inflammatory conditions like pyrexia and pain $[21,22]$. Taking the above facts into consideration and the lack of sufficient toxicological data regarding the simultaneous exposure of FQs and NSAIDs, we evaluated meloxicam, levo-floxacin, pazufloxacin and enrofloxacin for their effect on the plasma AOA that could give some insight of their basic toxicological profile. Since prolonged treatment of some drugs (zonisamide, topiramate, caffeine, etc) leads to body weight loss, drugs like antipsycotics, on the other hand, produce obesity in humans $[23,24]$. The assessment of body weight parameter would indicate general impact on metabolism in addition to generating data regarding the above cited effects of drugs on the body weight. This will also help in considering dosage corrections of these drugs when used for prolonged durations.

The availability of data on body weight with the co-administration of NSAIDs and FQs is also lacking. Thus, we also evaluated the effect of these drugs on body weight and correlated the body weight with AOA to determine any relation between the two parameters.

\section{Materials and Methods}

Animals: Thirty two male adult Soviet Chinchilla rabbits of 6 months of age, weighing around $3 \mathrm{Kg}$, were kept under normal ambient conditions, with an average day length of 11.5 hours, in a well-lighted experimental house. The animals were maintained on standard rabbit feed and ad libitum water.

Ethical approval: The experimental protocol was approved by the University Animal Ethics Committee under order No.VMC/13/17/86-1806 dated 4/4/13.

Experimental design: Rabbits were randomly divided to eight groups of four rabbits each. Group A, serving as control, was administered $5 \%$ dextrose. Group B, C, $\mathrm{E}$ and $\mathrm{G}$ were gavaged meloxicam, levofloxacin, pazufloxacin, and enrofloxacin, respectively, in 5\% dextrose. Levofloxacin and pazufloxacin were administered at the dose rate of $10 \mathrm{mg} / \mathrm{kg}$ body weight b.i.d $12 \mathrm{~h}$, that was extrapolated from the therapeutic dose in humans $[6,25]$, whereas the meloxicam $(0.2 \mathrm{mg} / \mathrm{Kg}$ body weight o.i.d.) and enrofloxacin $(20 \mathrm{mg} / \mathrm{kg}$ body weight o.i.d.) were used at their recommended therapeutic doses in rabbits [26,27]. Groups D, F and $\mathrm{H}$ were co-gavaged meloxicam with levofloxacin, pazufloxacin, and enrofloxacin, respectively, at the above dose rates.

Drugs: The drugs used were meloxicam (Melonex ${ }^{\circledR}$ Intas Pharma, India), levofloxacin hemihydrate (Levoflox ${ }^{\circledR}$, Cipla Pharma, India) pazufloxacin mesylate (Pazumac ${ }^{\circledR}$, Macleoids Pharma, India) and enrofloxacin (Enrocin ${ }^{\mathrm{TM}}$, Pfizer Animal Health, India).

Disclaimer about the drugs: The drugs used in the study are for information purpose only. Authors or institute of authors do not recommend the use of these drugs.

Plasma antioxidant activity analysis: Blood samples were collected from the ear vein of these animals in heparinized vials on $0,7,14$ and 21 day of treatment. The plasma AOA was determined by the method of Koracevic et al. [28] based on the principle that a standardized solution of Fe-EDTA complex reacts with hydrogen peroxide by a Fenton-type reaction, leading to the formation of hydroxyl radicals that degrade benzoate, resulting in the release of thio-barbituric acid reactive substances (TBARS). Antioxidants from the added plasma suppress TBARS production. This reaction was measured spectrophotometrically and the inhibition of color development is defined as the total antioxidant activity.

Body weight: Body weight was determined with an electronic weighing balance at $0,7,14$ and 21 days of treatment. These weekly body weight values were also used to make the necessary corrections in dose of the above drugs administered. The weekly determined body weight of each animal was expressed as the percentage of its zero day body weight to determine the trend in the body weight pattern.

Statistical analysis: All these results were subjected to analysis of variance carried in completely randomized design, and the significance was tested using Duncan's 
Table-1. Effect of meloxicam (group B), levofloxacin (group C), levofloxacin+meloxicam (group D), pazufloxacin (group E), pazufloxacin+meloxicam (group F), enrofloxacin (group G) and enrofloxacin+meloxicam (group $H$ ) on the plasma antioxidant activity ( $\mathrm{mmol} / \mathrm{L})$ in rabbits.

\begin{tabular}{lcccc}
\hline Group & Day 0 & Day 7 & Day 14 & Day 21 \\
\hline Group A (Control) & $1.24 \pm 0.056^{\mathrm{a}}$ & $1.18 \pm 0.035^{\mathrm{bcd}}$ & $1.17 \pm 0.049^{\mathrm{bc}}$ & $1.13 \pm 0.050^{\mathrm{c}}$ \\
Group B & $1.22 \pm 0.114^{\mathrm{a}}$ & $1.01 \pm 0.092^{\mathrm{a}}$ & $1.00 \pm 0.033^{\mathrm{a}}$ & $0.84 \pm 0.080^{\mathrm{a}}$ \\
Group C & $1.24 \pm 0.028^{\mathrm{a}}$ & $1.09 \pm 0.060^{\mathrm{ab}}$ & $1.22 \pm 0.058^{\mathrm{c}}$ & $1.09 \pm 0.014^{\mathrm{bc}}$ \\
Group D & $1.23 \pm 0.038^{\mathrm{a}}$ & $1.11 \pm 0.007^{\mathrm{abc}}$ & $1.10 \pm 0.031^{\mathrm{abc}}$ & $0.87 \pm 0.072^{\mathrm{ab}}$ \\
Group E & $1.33 \pm 0.041^{\mathrm{a}}$ & $1.12 \pm 0.016^{\mathrm{abc}}$ & $1.12 \pm 0.035^{\mathrm{abc}}$ & $0.80 \pm 0.086^{\mathrm{a}}$ \\
Group F & $1.28 \pm 0.017^{\mathrm{a}}$ & $1.15 \pm 0.035^{\mathrm{abcd}}$ & $1.15 \pm 0.026^{\mathrm{bc}}$ & $0.81 \pm 0.083^{\mathrm{a}}$ \\
Group G & $1.35 \pm 0.021^{\mathrm{a}}$ & $1.28 \pm 0.004^{\mathrm{d}}$ & $1.12 \pm 0.022^{\mathrm{abc}}$ & $0.76 \pm 0.063^{\mathrm{a}}$ \\
Group H & $1.26 \pm 0.038^{\mathrm{a}}$ & $1.25 \pm 0.050^{\mathrm{cd}}$ & $1.07 \pm 0.049^{\mathrm{ab}}$ & $0.70 \pm 0.131^{\mathrm{a}}$ \\
\hline
\end{tabular}

Values given are mean \pm standard error of mean for 4 animals

Means, in a column, with different superscript do not differ significantly

Table-2. Effect of meloxicam (group B), levofloxacin (group C), levofloxacin+meloxicam (group D), pazufloxacin (group E), pazufloxacin+meloxicam (group F), enrofloxacin (group G) and enrofloxacin+meloxicam (group $\mathrm{H}$ ) on body weight ( $\mathrm{Kg}$ ) in rabbits.

\begin{tabular}{lcccc}
\hline Group & Day 0 & Day 7 & Day 14 & Day 21 \\
\hline Group A (Control) & $3.21 \pm 0.04^{\mathrm{a}}$ & $3.33 \pm 0.04^{\mathrm{a}}$ & $3.43 \pm 0.05^{\mathrm{a}}$ & $3.56 \pm 0.05^{\mathrm{a}}$ \\
Group B & $3.07 \pm 0.07^{\mathrm{a}}$ & $3.18 \pm 0.08^{\mathrm{a}}$ & $3.31 \pm 0.09^{\mathrm{a}}$ & $3.25 \pm 0.09^{\mathrm{a}}$ \\
Group C & $3.08 \pm 0.08^{\mathrm{a}}$ & $3.19 \pm 0.07^{\mathrm{a}}$ & $3.23 \pm 0.06^{\mathrm{a}}$ & $3.20 \pm 0.06^{\mathrm{a}}$ \\
Group D & $3.06 \pm 0.08^{\mathrm{a}}$ & $3.22 \pm 0.07^{\mathrm{a}}$ & $3.24 \pm 0.07^{\mathrm{a}}$ & $3.23 \pm 0.06^{\mathrm{a}}$ \\
Group E & $3.13 \pm 0.08^{\mathrm{a}}$ & $3.40 \pm 0.08^{\mathrm{a}}$ & $3.36 \pm 0.10^{\mathrm{a}}$ & $3.37 \pm 0.09^{\mathrm{a}}$ \\
Group F & $3.23 \pm 0.09^{\mathrm{a}}$ & $3.33 \pm 0.12^{\mathrm{a}}$ & $3.36 \pm 0.12^{\mathrm{a}}$ & $3.31 \pm 0.13^{\mathrm{a}}$ \\
Group G & $3.09 \pm 0.11^{\mathrm{a}}$ & $3.26 \pm 0.12^{\mathrm{a}}$ & $3.30 \pm 0.13^{\mathrm{a}}$ & $3.43 \pm 0.10^{\mathrm{a}}$ \\
Group H & $3.22 \pm 0.01^{\mathrm{a}}$ & $3.24 \pm 0.01^{\mathrm{a}}$ & $3.34 \pm 0.01^{\mathrm{a}}$ & $3.55 \pm 0.01^{\mathrm{a}}$ \\
\hline
\end{tabular}

Values given are mean \pm standard error of mean for 4 animals

Means, in a column, with one common superscript do not differ significantly

multiple range test [29]. The results for AOA were correlated with body weight with Pearson's correlation. The significance was assayed at $5 \%(\mathrm{p}<0.05)$ levels. These statistical calculations were carried out with SPSS 16.0 software.

\section{Results and Discussion}

The results for the effect of meloxicam, levofloxacin, pazufloxacin and enrofloxacin on the plasma antioxidative activity in rabbits are presented in the Table-1. On the day 7 of treatment, the AOA of group B was significantly lower than the groups $A, G$ and $H$ with group $G$ having significantly higher values compared to groups $\mathrm{C}, \mathrm{D}$ and $\mathrm{E}$ and group $\mathrm{H}$ having significantly higher values than the group $\mathrm{C}$. The values of group $\mathrm{B}$ were significantly lower than the groups $\mathrm{A}, \mathrm{C}$ and $\mathrm{F}$ on the $14^{\text {th }}$ day of treatment, with group $\mathrm{C}$ also having the values significantly higher than the group $\mathrm{H}$. When compared to the two nonsignificantly different groups, $\mathrm{A}$ and $\mathrm{C}$, a significant decrease in the AOA was observed in the other treatment groups on the $21^{\text {st }}$ day of treatment. However, the AOA values of group $\mathrm{C}$ differed non-significantly from the group $\mathrm{D}$. The alterations in various parameters of antioxidant status/oxidative stress have been reported with FQs [30-32] or NSAIDs [15], although only a few studies are available about the effect of these drugs on AOA [15,33,34]. There are paucity of literature on the concurrent exposure of FQs and NSAIDs.

Elimination of xenobiotic requires ATP as the energy source. During the ATP synthesis from mitochondrial electron transport chain, a premature leakage of small number of electrons to oxygen forms reactive oxygen species (ROS) [35]. The biological outcome of mitochondrial ROS production and its potential involvement in physiological (signal transduction) versus pathological processes (oxidative stress induced disorders) depends on the balance between their production and detoxification [36]. Plasma AOA includes both enzymatic and nonenzymatic antioxidant systems [37], the measurement of which provides a holistic picture of antioxidant status than the measurement of individual antioxidant indices and is thus considered as a better marker of antioxidant status $[36,38]$ that could also help in assessment of oxidative status in vivo [39].

An initial response of body to ROS is the expression of Nrf-2, a transcription factor that increases the expression of genes mediating antioxidant response [40]. The significantly higher values of AOA in some of the treatment groups (group G versus groups B, C, D and $\mathrm{E}$ on day 7 of treatment and group $\mathrm{C}$ versus groups $\mathrm{B}$ and $\mathrm{D}$ on day 14 of treatment) could be attributed to this mechanism. However, consistently increasing exposure of pro-oxidative xenobiotics overwhelms the antioxidant status, by inhibiting the activity or sufficient synthesis of antioxidants, predisposing the cells to oxidative damage [41]. This might be incriminated as a reason for the significantly decreased levels of AOA observed in this study, especially at the $21^{\text {st }}$ day of treatment when all treated groups, except group $\mathrm{C}$, had significantly lower levels of AOA compared to the control group.

The results for the effect of meloxicam and the 


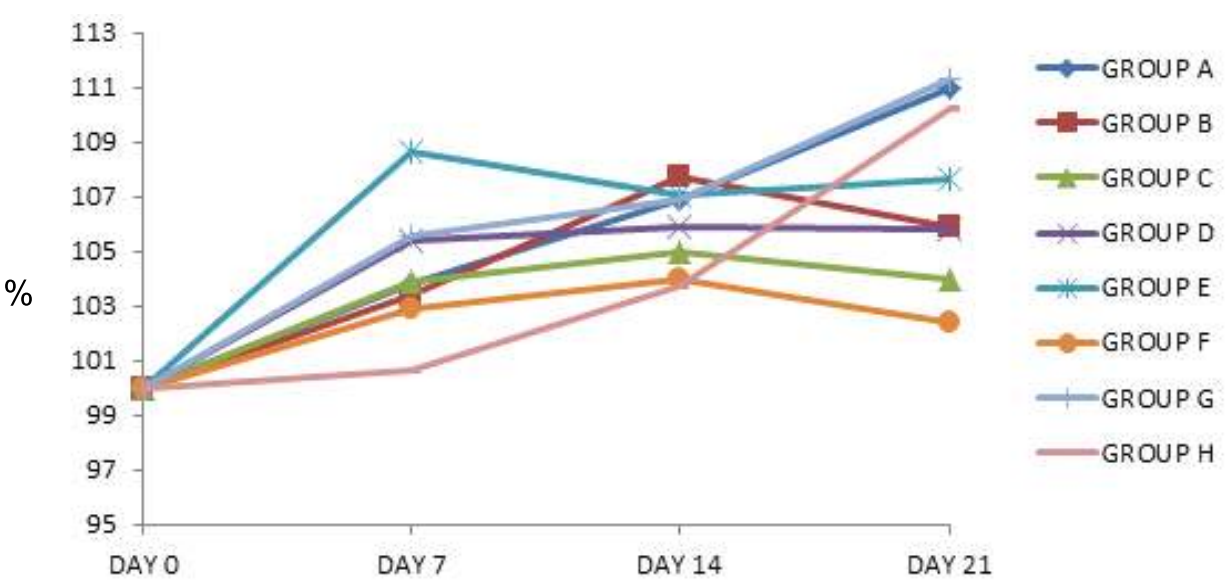

Figure-1. Comparative trend of body weight of control rabbits (Group A) versus rabbits administered meloxicam (group B), levofloxacin (group C), levofloxacin +meloxicam (group D), pazufloxacin (group E), pazufloxacin +meloxicam (group $\mathrm{F}$ ), enrofloxacin (group $\mathrm{G}$ ) and enrofloxacin +meloxicam (group $\mathrm{H}$ )

above FQs on body weight are presented in Table- 2 and Figure-1. The body weight of all the groups differed non-significantly from each other throughout the study period. A non-significant correlation was observed between AOA and body weight of each group which indicates that the predisposition to the pathological implications oxidative/antioxidant imbalance $[1,14$, $15,30,42-44]$ predicted from the estimation of parameters related to oxidative/anti-oxidant status $[32,42,45]$ cannot be predicted from body weight.

\section{Conclusion}

The results from this study indicate that meloxicam, pazufloxacin, and enrofloxacin reduce the body's AOA. Significant reduction in body's AOA also occurs when levofloxacin is co-treated with meloxicam. The body weight alterations induced by these drugs are non-significant. Since the alterations in antioxidant status is both predisposing and precipitating factor in the pathogenesis of several diseases and toxicities, these drugs should be used with caution for prolonged periods of time, especially, when the slow rate of elimination due to compromised hepatic and renal clearances, as seen in geriatric patients, enhances their plasma levels and hence the toxicity.

\section{Authors' contributions}

Both authors contributed equally. Both authors read and approved the final manuscript.

\section{Acknnowledgements}

The current research has been carried out at the Department of Pharmacology and Toxicology, GADVASU, Ludhiana. The study is a part of the research project, "Evaluation of retinopathic potential of fluoroquinolones" assigned by University Grants Commission, India to the Department of Veterinary Pharmacology and Toxicology, GASVASU, Ludhiana under letter no. FNo. 40-279/2011(SR). Financial assistance to the project has been made by University Grants Commission, India.

\section{Competing interests}

The authors declare that they have no competing interests.

\section{References}

1. Gunes, V., Cinar, M., Onmaz, A. C., Atalan, G. and Yavuz, U. (2011) Effects of Meloxicam on oxidative deterioration due to exercise in horses. Revue. Med. Vet., 162: 258-264.

2. Blondeau, J. M. (1999) Expanded activity and utility of the new fluoroquinolones: a review. Clin. Ther, 21:3-40.

3. Martinez, M., McDermott, P. and Walker, R. (2006) Pharmacology of the fluoroquinolones: a perspective for the use in domestic animals. Vet. J., 172: 10-28.

4. Fernandez, J., Barrett, J. F., Licata, L., Amaratunga, D. and Frosco, M. (1999) Comparison of efficacies of oral levofloxacin and oral ciprofloxacin in a rabbit model of a staphylococcal abscess. Antimicrob. Agents. Chemother., 43(3): 667

5. Zhanel, G. G., Fontaine, S., Adam, H., Schurek, K., Mayer, M., Noreddin, A. M., Gin, A. S., Rubinstein, E. and Hoban, D. J. (2006) A review of new fluoroquinolones: focus on their use in respiratory tract infections. Treat. Respir. Med., 5: 437465.

6. Vora, A. (2009) Pazufloxacin. J.Assoc. Physicians. India., 57.

7. Mitchell, M. A. (2006) Enrofloxacin. J. Exot. Pet. Med., 15(1): 66-69.

8. Zhao, B., Chingnell, C. F., Rammal, M., Smith, F., Hamilton, M. G., Andley, U. P. and Roberts, J. E. (2010) Detection and prevention of ocular phototoxicity of ciprofloxacin and other fluoroquinolone antibiotics. Photochem. Photobiol., 86(4): 798-805

9. Levofloxacin, Wikipedia, http://en.wikipedia.org/wiki/ Levofloxacin (Acessed on 20 September 2013).

10. Schmidt, U. and Schlüter, G. (1996) Studies on the mechanism of phototoxicity of Bay y3118 and other quinolones. Adv. Exp. Med. Biol., 387: 117-120.

11. Thuong-Guyot, M., Domale, O., Pocidalo, J. J. and Hayem, G. (1994) Effects of flouroquinolones on cultured articular condrocytes flow cytometric analysis of free radical production. J. Pharmacol. Exp. Ther., 271: 1544-1549.

12. Yazar, E. and Tras, B. (2001) Effects of fluoroquinolone antibiotics on hepatic superoxide dismutase and glutathione peroxidase activities in healthy and experimentally induced peritonitis mice. Revue. Med. Vet., 152(3): 235-238.

13. Ozgocmen, S., Ardicoglu, O., Erdogan, H., Fadillioglu, E. and Gudul, H. (2005) In vivo effect of celecoxib and tenoxicam on oxidant/anti-oxidant status of patients with knee osteoarthritis. Ann. Clin. Lab. Sci., 35: 137-143.

14. Edfawy, M., Hassan, M. H., Mansour, A., Hamed, A. A. and Amin, H. A. (2012) Meloxicam modulates oxidative stress status, inhibits prostaglandin E2, and abrogates apoptosis in carbon tetrachloride-induced rat hepatic injury. Int. J. Toxicol., 31(3): 276-286.

15. Burak Cimen, M. Y., Cimen, O. B., Eskandari, G., Sahin, G., Erdogan, C. and Atik, U. (2003) In vivo effects of meloxicam, celecoxib, and ibuprofen on free radical metabolism in human erythrocytes. Drug. Chem. Toxicol., 26(3): 169-176.

16. Villegas, I., Martin, M. J., La Casa, C., Motilva, V. and De La 
Lastra, C. A. (2002) Effects of oxicam inhibitors of cyclooxygenase on oxidative stress generation in rat gastric mucosa. a comparative study. Free. Radic. Res., 36(7): 769777.

17. Li, H., Hortmann, M., Daiber, A., Oelze, M., Ostad, M. A., Schwarz, P. M., Xu, H., Xia, N., Kleschyov, A. L., Mang, C., Warnholtz, A., Munzel, T. and Forstermann, U. (2008) Cyclooxygenase 2-selective and nonselective nonsteroidal anti-inflammatory drugs induce oxidative stress by upregulating vascular NADPH oxidases. J. Pharmacol. Exp. Ther., 326(3): 745-753.

18. Suresh, D. R., Annam, V., Pratibha, K. and Prasad, B. V. (2009) Total antioxidant capacity-a novel early biochemical marker of oxidative stress in HIV infected individuals. J. Biomed. Sci., 16: 61.

19. Nagy, G., Ward, J., Mosser, D. D., Koncz, A., Gergely, P. Jr., Stancato, C., Qian, Y., Fernandez, D., Niland, B., Grossman, C. E., Telarico, T., Banki, K. and Perl, A. (2006) Regulation of CD4 expression via recycling by HRES-1/RAB4 controls susceptibility to HIV infection. J. Biol. Chem., 281(45): 34574-34591.

20. Motoyama, T., Okamoto, K., Kukita, I., Hamaguchi, M., Kinoshita, Y. and Ogawa, H. (2003) Possible role of increased oxidant stress in multiple. Care. Med., 31: 10481052.

21. Lipsky, B. A., Byren, I. and Hoey, C. T. (2010) Treatment of Bacterial Prostatitis. Clin. Infect. Dis., 50(12): 1641-1652.

22. Wagenlehner, F. M. E. and Krieger, J. N. (2011) Treatment of chronic bacterial prostatitis. Pelviperineol., 30: 17-26.

23. Gadde, K. M., Franciscy, D. M., Wagner, H. R. and Krishnan, K. R. (2003) Zonisamide for weight loss in obese adults: a randomized controlled trial. J. Am. Med. Assoc., 289(14): 1820-1825.

24. Sicras-Mainar, A., Navarro-Artieda, R., Rejas-Gutiérrez, J. and Blanca-Tamayo M. (2008) Relationship between obesity and antipsychotic drug use in the adult population: A longitudinal, retrospective claim database study in Primary Care settings. Neuropsychiatr. Dis. Treat., 4(1): 219-226.

25. Croisier, D., Chavanet, P., Lequeu, C., Ahanou, A., Nierlich, A., Neuwirth, C., Piroth L., Duong, M., Buisson, M. and Portier, H. (2002) Efficacy and pharmacodynamics of simulated human-like treatment with levofloxacin on experimental pneumonia induced with penicillin-resistant pneumococci with various susceptibilities to fluoroquinolones. J. Antimicrob. Chemother., 50(3): 349-360.

26. Mayer, J. (2007) Analgesia and anesthesia in rabbits and rodents. Proceedings: Western Veterinary Conference.

27. Adamcak, A. and Otten, B. (2000) Rodent Therapeutics. Vet. Clin. N.Am: Exotic. Anim. Pract. 3: 221-240.

28. Koracevic, D., Koracevic, G., Djordjevic, V., Andrejevic, S. and Cosic, V. (2001) Method for the measurement of antioxidant activity in human fluids. J. Clin. Pathol., 54: 356-361.

29. Duncan, D. B. (1995) Multiple range and multiple F-tests. Biometrics., 11: 1-14.

30. Rampal, S., Kaur, R., Sethi, R., Singh, O. and Sood, N. (2008) Ofloxacin-associated retinopathy in rabbits: role of oxidative stress. Human. Exp. Toxicol., 27: 409-415.

31. Li, Q., Peng, S., Sheng, Z. and Wang, Y. (2010) Ofloxacin induces oxidative damage to joint chondrocytes of juvenile rabbits: excessive production of reactive oxygen species, lipid peroxidation and DNA damage. Eur. J. Pharmacol., 25:626(2-3): 146-153.

32. Talla, V. and Veerareddy, P. R. (2011) Oxidative stress induced by fluoroquinolones on treatment for complicated urinary tract infections in Indian patients. J. Young. Pharm., 3:304-309.

33. Arafa, N. M., Abdel-Rahman, M., El-khadragy, M. F. and Kassab, R. B. (2013) Evaluation of the possible epileptogenic activity of ciprofloxacin: the role of Nigella sativa on amino acids neurotransmitters. Neurochem. Res., 38(1): 174185.

34. Araniciu, C., Parvu, A. E., Tiperciuc, B., Palage, M., Oniga, S., Verite P. and Oniga, O. (2013) Synthesis and evaluation of the anti-inflammatory activity of some 2-(trimethoxyphenyl)-4-r1-5-r2-thiazoles. Dig. J. Nanomatr. Bios., 8(2): 699-709.

35. Kovacic, P, Pozos, R. S., Somanathan, R., Shangari, N. and O'Brien, P. J. (2005) Mechanism of mitochondrial uncouplers, inhibitors, and toxins: Focus on electron transfer, free radicals, and structure-activity relationships. Curr. Med. Chem., 12: 2601-2623.

36. Valko, M., Leibfritz, D., Moncola. J., Cronin, M. T. D., Mazura, M. and Telser, J. (2007) Free radicals and antioxidants in normal physiological functions and human disease. Int. J. Biochem. Cell. Biol., 39: 44-84.

37. Berzosa, C., Cebrian, I., Fuentes-Broto, L., Gomez-Trullen, E., Piedrafita, E., Martinez-Ballarin, E., Lopez-Pingarron, L., Reiter, R. J. and Garcia, J. J. (2011) Acute exercise increases plasma total antioxidant status and antioxidant enzyme activities in untrained men. J. Biomed. Biotechnol., 540458.

38. Kaur, S., Verma, I., Narang, A. P. S., Chinna, R. S., Singh, P. and Aggarwal, S. P. (2011) Assessment of total antioxidant status in acute pancreatitis and prognostic significance. Int. J. Biol. Med. Res., 2(2): 575-576.

39. Ghiselli, A., Serafini, M., Natella, F. and Scaccini, C. (2000) Total antioxidant capacity as a tool to assess redox status: critical view and experimental data. Free. Radic. Biol. Med., 29(11): 1106-1114.

40. Ristow, M. and Schmeisser, S. (2011) Extending life span by increasing oxidative stress. Free. Rad. Biol. Med., 51: 327336.

41. Mytilineou, C., Kramer, B. C. and Yabut, J. A. (2002) Glutathione depletion and oxidative stress. Parkinsonism. Relat. Disord., 8: 385-387.

42. Dubey, N., Khan, A.M. and Raina, R. (2013) Sub-acute deltamethrin and fluoride toxicity induced hepatic oxidative stress and biochemical alterations in rats. Bull. Environ. Contam. Toxicol., 91:334-338.

43. Khan, A. M., Dubey, N., Raina, R., Singh, G. and Beigh, S. A. (2013) Toxic effects of deltamethrin and fluoride on hematological parameters in rats. Fluoride., 46(1):34-38.

44. Khan, A. M., Sultana, M., Raina, R., Dubey, N. and Dar, S. A. (2013) Effect of sub-acute toxicity of bifenthrin on antioxidant status and hematology after its oral exposure in goats. Proc. Natl. Acad. Sci. India. Sect B. Biol. Sci., 83(4): 545-549.

45. Dar, M. A., Khan, A. M., Raina, R., Verma, P. K. and Sultana, M. (2013) Effect of repeated oral administration of bifenthrin on lipid peroxidation and anti-oxidant parameters in Wistar rats. Bull. Environ. Contam. Toxicol., 91: 125-128. 